\title{
Sampah Plastik Sebagai Potensi dalam Pembuatan Bahan Bakar Minyak
}

\author{
Rudy Yoga Lesmana, Nani Apriyani \\ Program Studi Teknik Lingkungan Fakultas Teknik Universitas Muhammadiyah Palangkaraya \\ Surel: yoga.lesmana@umpalangkaraya.ac.id
}

\begin{abstract}
ABSTRAK
Kuantitas limbah plastik saat ini memang sangat sulit untuk dikelola. Salah satu solusi untuk mengurangi pertumbuhan sampah plastik yaitu dengan membuatnya menjadi bahan bakar alternatif, yaitu minyak mentah. Tujuan Penelitian ini adalah untuk menciptakan minyak mentah sebagai energi alternatif dari sampah plastik dan untuk membandingkan kuantitas minyak hasil olahan sampah plastik berjenis PE dan PET dengan bahan bakar konvensional. Metodologi peneilitian antara lain mengumpulan sampel berupa sampah plastik yang berbahan baku PP, PE dan PET melakukan pembuatan reaktor dan mengolah sampel menjadi minyak mentah, melihat kuantitas minyak mentah hasil olahan, melakukan pengujian nilai kalor minyak mentah hasil olahan berdasarkan bahan baku plastik, dan melakukan perbandingan nilai kalor minyak mentah hasil olahan dengan bahan bakar konvensional. Hasil penelitian menunjukan bahwa minyak dari plastic kuantitas minyak hasil olahan dari PE dan PET yaitu sebanyak $425 \mathrm{ml}$ dan PET tidak menghasilkan minyak, dan hanya menghasilkan serbuk berwarna putih.
\end{abstract}

Kata kunci

\section{PENDAHULUAN}

Sampah merupakan masalah umum bagi negara maju maupun negara berkembang, hal tersebut diakibatkan oleh meningkatnya jumlah penduduk, sehingga kuantitas limbah yang dihasilkan juga meningkat meskipun pengumpulan sampah, pemisahan dan pembuangan telah dilakukan namun akan menjadi masalah lama yang belum dapat terselesaikan dan akan tetap menjadi masalah di masa depan jika tidak ada inisiatif untuk menyelesaikannya. Kesalahan dalam pengelolaan limbah akan mengakibatkan masalah lingkungan yang serius seperti pencemaran air tanah, banjir, polusi udara dan perubahan iklim ${ }^{[1]}$. Salah satu permasalahan sampah yang sampai saat ini sulit untuk dikelola yaitu sampah plastik. Penggunaan sampah plastik saat ini mengalami peningkatan dari hari ke hari.

Plastik dapat dikelompokkan menjadi dua macam yaitu thermoplastik dan termosetting. Thermoplastik adalah bahan plastik yang jika dipanaskan sampai temperatur tertentu, akan mencair dan dapat dibentuk kembali menjadi bentuk yang diinginkan. Sedangkan thermosetting adalah plastik yang jika telah dibuat dalam bentuk padat, tidak dapat dicairkan kembali dengan cara dipanaskan ${ }^{[2]}$. Surono dan Ismanto $^{[3]}$ mengemukakan bahwa Berdasarkan sifat kedua kelompok plastik di atas, thermoplastik adalah jenis yang memungkinkan untuk didaur ulang. Jenis-jenis plastik yang paling 
sering diolah adalah polyethylena (PE), polypropylene (PP), polistirena (PS), polyethylene terephthalate (PET) dan polyvinyl chloride (PVC).

Salah satu solusi untuk mengurangi pertumbuhan sampah plastik yaitu dengan membuatnya menjadi bahan bakar alternatif, yaitu minyak mentah, selain untuk membantu mengurangi jumlah plastik hal tersebut juga untuk membuat kualitas lingkungan menjadi lebih baik. ini juga membantu menghasilkan bahan bakar yang ketika diubah menjadi bentuk yang nyaman dapat digunakan sebagai sumber energi.

Penanganan sampah plastik yang saat ini banyak diteliti dan dikembangkan adalah mengkonversi sampah plastik menjadi bahan bakar minyak. Dengan cara ini dua permasalahan penting bisa diatasi, yaitu bahaya menumpuknya sampah plastik dan diperolehnya kembali bahan bakar minyak yang merupakan salah satu bahan baku plastik. Teknologi untuk mengkonversi sampah plastik menjadi bahan bakar minyak yaitu dengan proses cracking (perekahan). Salah satu proses perekahan (cracking) adalah thermal cracking. Proses konversi sampah plastik menjadi bahan bakar minyak dengan metode thermal cracking dipengaruhi oleh beberapa parameter antara lain jenis plastik, temperatur pyrolisis, tipe reaktor pyrolisis, laju pemasukan kalor, temperatur kondensasi dan lain-lain ${ }^{[3]}$. Limbah plastik berkontribusi terhadap masalah lingkungan dan sosial yang besar karena hilangnya sumber daya alam, pencemaran lingkungan, menipisnya ruang timbunan sampah ${ }^{[4]}$.

Nasrun et $a l^{[5]}$ mengemukakan bahwa Proses pengolahan sampah plastik menjadi bahan bakar meliputi beberapa proses, diantaranya pirolisis dan distilasi. Tamilkolundu dan Murugesan ${ }^{[6]}$, melakukan penelitian dengan mengubah sampah plastik jenis PVC menjadi bahan bakar minyak. Bahan bakar minyak dari plastik PVC ini mempunyai densitas 7\% lebih tinggi dari solar. Demikian juga dengan viskositasnya, lebih tinggi 300\% disbanding solar. efisiensi termal yang lebih tinggi.

Tujuan penelitian ini adalah membandingkan kuantitas minyak hasil olahan sampah plastik berjenis PE, PP dan PET, membandingkan nilai kalor dari minyak hasil olahan sampah plastik berjenis PE, PP dan PET.

\section{METODE PENELITIAN}

\section{Tahapan Penelitian}

1. Mengumpulan sampel berupa sampah plastik yang berbahan baku PE, PP dan PET.

2. Membuat reaktor dan megolah sampel menjadi minyak mentah.

3. Mencatat kuantitas minyak mentah hasil olahan.

4. Melakukan pengujian nilai kalor minyak mentah berdasarkan bahan baku plastik.

\section{Variabel Penelitian}

Variabel dalam penelitian ini terdiri dari variabel bebas yaitu sampah plastik yang terdapat di Kota Palangka Raya dan variabel terikat yaitu minyak hasil olahan.

\section{Teknik Pengumpulan Data}

Data yang digunakan dalam penelitian ini terdiri dari data primer dan data sekunder.Data primer dalam penelitian ini adalah: (a) Jumlah Sampah Plastik dan (b) kuantitas minyak Mentah Hasil Olahan.

\section{Observasi lapangan}

Observasi ini dilakukan dalam rangka meninjau tempat pengumpulan sampel, pembuatan reaktor dan proses pengolahan sampel menjadi minyak.

\section{Prosedur Kerja di Lapangan}

Penelitian ini dilakukan dengan metode eksperimen. Bahan yang digunakan yaitu: plastik berjenis PE, PP dan PET yang sudah dicacah dan mengolah sampah plastik menjadi bahan bakar minyak dengan menggunakan reaktor. Reaktor berfungsi untuk menguapkan sampah plastik. Uap plastik kemudian dikondensasikan di dalam kondenser. Hasil kondensasinya ditampung di penampung minyak sedangkan gas yang tidak terkondensasi dialirkan ke burner untuk dibakar. Alat yang juga digunakan adalah termometer, kompor, gelas ukur, stopwatch dan timbangan. 
Langkah pengolahan sampel dilakukan dengan langkah sebagai berikut.

1. Menimbang sampah plastik jenis PP sebanyak $0,5 \mathrm{~kg}$ dan memasukkan ke dalam reaktor pemanas.

2. Menghidupkan pompa untuk mengalirkan air pendingin kondenser.

3. Memanaskan reaktor pemanas dengan kompor gas sampai plastik menguap.

4. Mencatat banyaknya BBM yang terkumpul di dalam tabung penampung.

5. Mengulangi pengujian untuk jenis plastik lain (PET dan PE).

\section{Metode Analisis Data}

Analisis data dilakukan untuk mengetahui kuantitas minyak hasil olahan. Penentuan Kuantitas Minyak dilakukan dengan menuangkan minyak ke dalam gelas ukur berdasarkan proses pembakaran masingmasing $100 \mathrm{~kg}$ sampah plastik berjenis PE, PP dan PET.

\section{HASIL DAN PEMBAHASAN Plastik PE, PP dan PET Serta Kuantitas Minyak}

Pengujian dilakukan dengan Jenis Plastik PE dan PET, sedangkan untuk plastik berjenis PP tidak dapat dilakukan karena bahan baku sulit untuk didapatkan jika berasal dari barang bekas, sehingga penggunaan sampah jenis PP untuk pembuatan bahan bakar alternatif diabaikan. Sampah plastik yang digunakan sebagai bahan baku adalah sampah plastik yang telah dicacah, seperti pada Gambar 1.

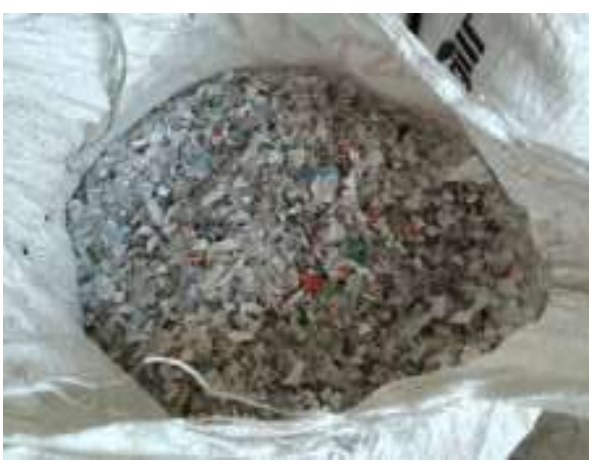

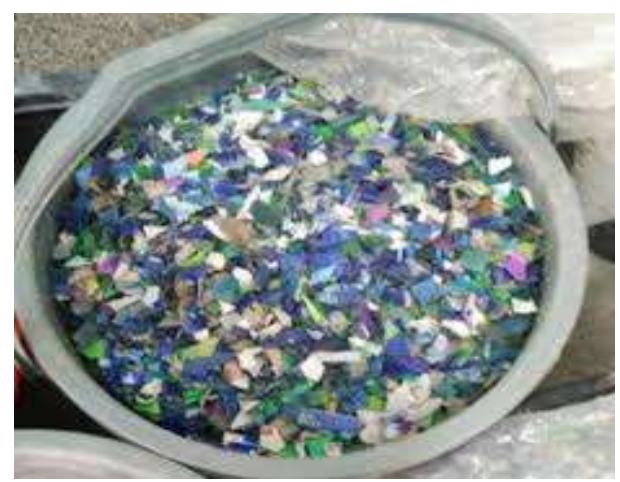

Gambar 1. Cacahan sampah plastik

Dengan demikian pengujian ini dilakukan untuk mengetahui karakteristik bahan bakar minyak yang dihasilkan dari plastik jenis PET dan PE saja. Dari pengujian diperoleh hasil pada Tabel 1 berikut.

Tabel 1. Proses pengolahan plastik PE dan PET menjadi bahan bakar minyak

\begin{tabular}{ccc}
\hline $\begin{array}{c}\text { Jenis } \\
\text { plastik }\end{array}$ & $\begin{array}{c}\text { Waktu } \\
\text { pengolahan } \\
\text { (menit) }\end{array}$ & $\begin{array}{c}\text { Minyak yang } \\
\text { dihasilkan } \\
(\mathrm{ml})\end{array}$ \\
\hline PE & 120 & 80 \\
& 240 & 240 \\
PET & 360 & 342 \\
& 120 & 0 \\
& 240 & 0 \\
\hline
\end{tabular}

Perbandingan waktu olahan dari plastik PE dan PET terhadap volume minyak ditunjukkan pada Gambar 2.

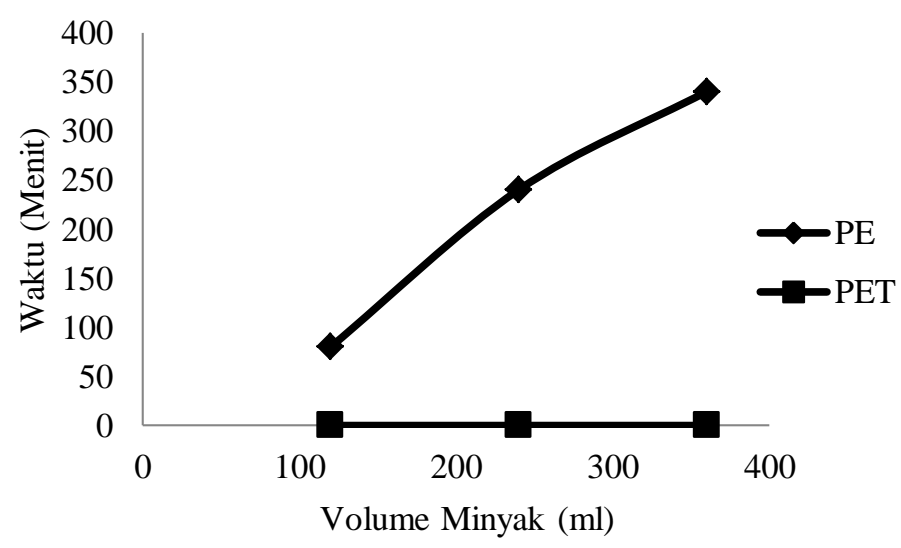

Gambar 2. Grafik perbandingan waktu olahan 
Pada Tabel 1 dan gambar 2 dapat dilihat bahwa pada pengolahan minyak dengan menggunakan bahan baku plastik PET, tidak menghasilkan minyak sama sekali dan plastik berjenis PET hanya menghasilkan serbuk putih yangmenempel pada bagian dalam reaktor dan pipa outlet. Pada proses pembakaran dengan durasi 120 menit hingga 360 hanya menghasikan uap dan tidak menghasilkan cairan berupa minyak.

Pengolahan minyak dengan bahan baku plastik berjenis PE dengan durasi waktu yang sama, menghasilkan minyak berturut-turut yaitu sebanyak 80, 240 dan $342 \mathrm{ml}$. Hal ini menjadikan bahan baku plastik PE layak untuk dijadikan bahan bakar alternatif pada penelitian lanjutan. Minyak hasil olahan ditunjukkan pada Gambar 3 berikut.

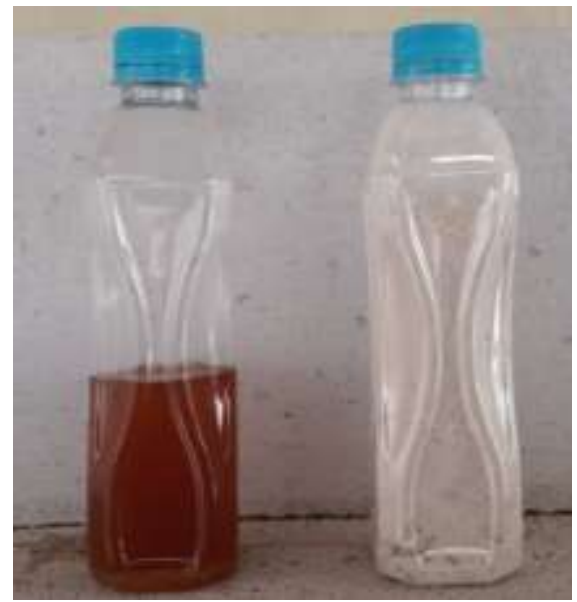

Gambar 3. Minyak dari Plastik Jenis PET dan Serbuk dari Plastik jenis PE

Hal ini sesuai dengan hasil penelitian Surono et al, 2016 yang menyatakan bahwa plastik jenis PP adalah jenis plastik yang paling bagus bila diolah menjadi bahan bakar. Pada pengolahan plastik PP, LPG yang dipakai adalah paling sedikit dengan jumlah minyak yang dihasilkan lebih banyak dari plastik jenis PE. Jenis plastik PET tidak menghasilkan minyak melaikan serbuk berwarna kekuning-kuningan.

\section{KESIMPULAN}

Hasil penelitian menunjukan bahwa minyak dari plastic kuantitas minyak hasil olahan dari PE dan PET yaitu sebanyak $425 \mathrm{ml}$ dan PET tidak menghasilkan minyak, dan hanya menghasilkan serbuk berwarna putih.

\section{UCAPAN TERIMA KASIH}

Ucapan terima kasih disampaikan kepada Kemenristekdikti atas pendanaan pada penelitian ini melalui Hibah Penelitian Dosen Pemula Tahun Anggaran 2019 berdasarkan Surat Keputusan Lembaga Penelitian dan Pengabdian kepada Masyarakat (LP2M) Universitas Muhammdiyah Palangkaraya dan Surat Perjanjian Kontrak Penelitian bagi Dosen Tetap Universitas Muhammadiyah Palangkaraya Pembiayaan Kemenristekdikti Tahun Anggaran 2019 Nomor: 348.a/PTM.63.R10/LP2M/N/2019.

\section{REFERENSI}

[1] Rapsing, E. C., Jr., Espinosa, E. B., 2016, Design and Fabrication of Waste Plastic Oil Converter, International Journal of Interdisciplinary Research and Innovations, 4 (2), 69-77.

[2] UNEP (United Nations Environment Programme), 2009, Converting Waste Plastics Into a Resource, Division of Technology, Industry and Economics International Environmental Technology Centre, Osaka/Shiga.

[3] Surono,U.B., Ismanto, 2016, Pengolahan Sampah Plastik Jenis PP, PET dan PE Menjadi Bahan Bakar Minyak dan Karakteristiknya, Jurnal Mekanika dan Sistem Termal, 1(1), 32-37.

[4] Sarker, M., Rashid, M.M., Rahman, M.S., Molla, M., 2012, Envirnmentally Harmful Low Density Waste Plastic Conversion into Kerosene Grade Fuel, Journal of Environmental Protection, 3, 700708.

[5] Nasrun, K., Eddy., Sari, I., 2015. Pengolahan Limbah Kantong Plastik Jenis Kresek Menjadi Bahan Bakar Menggunakan Proses Pirolisis, Jurnal Energi Elektrik, IV (1).

[6] Tamilkolundu, S., Murugesan, C., 2012, The Evaluation of blend of Waste Plastic Oil-Diesel fuel for use as alternate fuel for transportation, 2nd International Conference on Chemical, Ecology and Environmental Sciences, Singapore. 